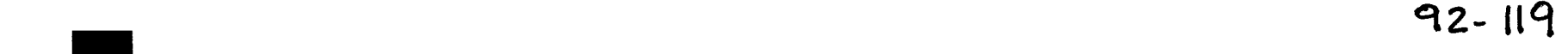

NENT OF

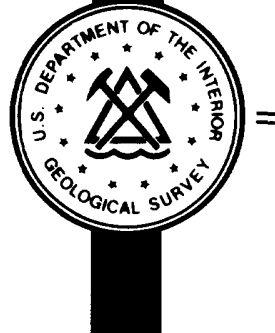

W

过區圆

\title{
ADVANTAGES AND LIMITATIONS OF WATER-SUPPLY ALTERNATIVES
}

\section{INTRODUCTION}

The increasing demand for water in the Nation's communities has created a need for educating community leaders about water-supply systems. A workshop titled "Water Systems for Small Communities" has been developed by the Ohio Cooperative Extension Service, in cooperation with the U.S. Geological Survey and other organizations, to help Ohio communities evaluate water-supply alternatives. This fact sheet summarizes some of the advantages and limitations of water-supply alternatives discussed in the workshop (see table).

\section{WATER-SUPPLY ALTERNATIVES}

The principal water-supply alternatives discussed in the workshop are direct use of surface water and ground water, purchase of water from a private water supplier or another community, and water conservation. These alternatives are described below, and some of the terms associated with them are defined.

\section{Surface Water}

The two most common surface-water-supply alternatives for small communities are offstream reservoirs and onstream reservoirs. An offstream reservoir is a earth structure designed to store water. A pumping station, if gravity flow is not possible, and pipeline are required to transport water from a natural source to the offstream reservoir. Onstream reservoirs, as the name implies, are designed to impound water within the source's main channel. The main components of an onstream reservoir are the dam (earth and (or) metal and concrete) and the spillway. Both types of reservoirs can be designed for multiple uses, such as public water supply, industrial water use, and recreation. Onstream reservoirs also can provide flood control. One difference between the two types of reservoirs is their ability to make full use of the potential water capture rate. The capture rate is a measure of a reservoir's ability to intercept runoff from precipitation and snowmelt. The offstream reservoir's design inhibits runoff as a water-replenishment source. The principal environmental concern with onstream reservoirs is their disruption of a stream's ecosystem. The onstream reservoir transforms part of a free-flowing stream into a ponded, controlled water source. The transformation changes the nature of the ecosystem, which can lead to losses and (or) changes in the plant and animal species associated with the stream's natural ecosystem.

\section{Ground Water}

A ground-water supply for a small community typically consists of either a single large well or a system of smaller wells that collectively supply sufficient water to meet community needs. Groundwater yields are variable throughout Ohio. Yields in northwestern Ohio are commonly 100 to more than 500 $\mathrm{gal} / \mathrm{min}$ (gallons per minute) per well, whereas yields in the southeast are more likely to be less than $5 \mathrm{gal} / \mathrm{min}$. Most of Ohio's ground-water supply meets the Ohio Environmental Protection Agency drinking-water standards without treatment, although water softeners are commonly used to reduce hardness and concentrations of iron. Potential contaminants to water supply sources resulting from human activities include leachate from on-site sewage systems (septic tanks), hydrocarbon leaks and spills, brine from oil and gas drilling, acids and toxic metals from mining and industrial activities, and pesticides.

\section{Purchased Water}

Some communities choose to purchase water from outside sources rather than develop a new surface- or ground-water source. The community that exercises this option may give up its control over certain aspects of the water-supply system and thus may not be an active participant in decisions affecting its water supply. The most notable loss of control lies in establishing water rates.

\section{Water Conservation}

One solution to problems of increasing water demand is to try to reduce the demand through waterconservation programs rather than seek to meet the demand by developing or expanding water supplies. Supply-side management programs (reduction of water losses within the delivery system) include water audits and leak detections. Demand-side management (reduction of water use by modifying customer behavior) can be accomplished through ordinances, incremental water rates, and education. Successful 


\section{Advantages}

- Site flexibility compared with onstream reservoirs

- Potential for incremental development

- Selective withdrawal of source water

- Mitigation of environmental disruption

- Multipurpose use

- No pump or pipeline from source to reservoir required

- Higher capture rate compared with offstream reservoirs

- Multipurpose use

Generally less expensive to develop than surface water

- Operation and maintenance less expensive than for surface water

- Environmental disruption associated with surface water development is avoided

- Reduced capital expenses

- No development of source expenses

- Water-treatment facility unnecessary

- Increased water-source longevity

- Infrastructure projects delayed

- Reduced treatment expenses

\section{Limitations}

Surface Water -- Offstream Reservoirs

- Operation and maintenance expenses commonly higher than for onstream reservoirs

- Lower capture rate compared with onstream reservoirs

- May require a lowhead dam

\section{Surface Water -- Onstream Reservoirs}

- Potential contamination from point and nonpoint sources

- Dam/spillway expense

- Environmental disruption

\section{Ground Water}

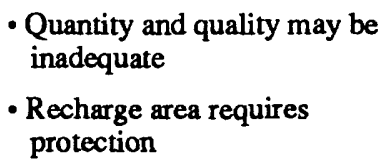

Purchased Water

- Loss of autonomy

- Limited control of water rates

Water Conservation

- May reduce revenues initially water-conservation programs may reduce revenues initially, therefore a community may need to adjust its water-rate structure so that revenues equal the cost of providing water to its customers.

\section{ACKNOWLEDGMENTS}

The author would like to thank Dr. Karen Mancl of the Ohio Cooperative Extension Service for her help in the table design for this Fact Sheet. Additional valuable assistance with the terminology of this Fact Sheet was given by Richard Bartz, Leonard Black, and Peter Thompson of the Ohio Department of Natural Resources, Division of Water.

\section{ADDITIONAL INFORMATION}

Additional information about "Water Systems for Small Communities" and the organizations participating in the workshop can be obtained from:

Ohio Cooperative Extension Service

The Ohio State University

590 Woody Hayes Drive

Columbus, Ohio 43210

Open-File 92-119

R. J. Veley, 1992 